\title{
Radiotherapy Recommendations in Covid-19 Pandemia: Mini-Review
}

\author{
Bora Uysal*, Hakan Gamsız, Ferrat Dincoglan, Omer Sager, Selcuk Demiral and \\ Murat Beyzadeoglu \\ Department of Radiation Oncology, Turkey
}

\section{ISSN: 2637-773X}

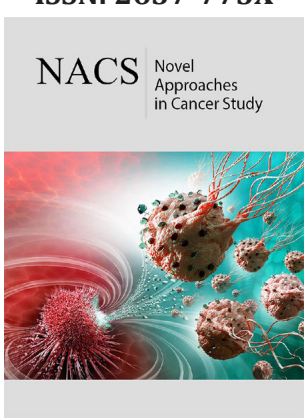

*Corresponding author: Bora Uysal, Department of Radiation Oncology, University of Health Sciences, Gulhane Medical Faculty, Turkey

Submission: 畊 April 15, 2020

Published: 垉July 06, 2020

Volume 5 - Issue 1

How to cite this article: Bora Uysal, Hakan Gamsız, Ferrat Dincoglan, Omer Sager, Selcuk Demiral, Murat Beyzadeoglu. Radiotherapy Recommendations in Covid-19 Pandemia: Mini-Review. Nov Appro in Can Study. 5(1). NACS.000601. 2020. DOI: 10.31031/NACS.2020.05.000601

Copyright@ Bora Uysal, This article is distributed under the terms of the Creative Commons Attribution 4.0 International License, which permits unrestricted use and redistribution provided that the original author and source are credited.

\begin{abstract}
Management of cancer with radiotherapy during the severe acute respiratory syndrome coronavirus 2 (SARS-CoV-2) pandemic is a novel and risky situation because of the higher mortality rates of COVID19 infection in immune compromised patients. To receive or to delay radiotherapy is a challenging topic with different scenarios. We reviewed updated literature and share some recommendations to the problems that every department of Radiation Oncology might face worldwide.
\end{abstract}

\section{Introduction}

Coronaviruses are one of the human and animal pathogens. A new coronavirus type was identified after pneumonia cases in Wuhan which is a city of China at the last month of 2019. This novel type of coronavirus resulted an epidemic throughout China and increasing number of cases in other countries worldwide [1]. In February 2020, the WHO (World Health Organization) announced the disease COVID-19 that representing coronavirus disease 2019. Severe acute respiratory syndrome that required intensive care is the possible complication of COVID-19 and can be fatal.

The WHO made a statement about the COVID-19 and initiated to characterize this disease as a pandemic to emphasize the important situation and warn the countries to act for detecting infection and preventing spread. Protection of health workers, older adults and those people with comorbid diseases were the highest priorities of the WHO. More than 1-meter social distancing, to wash hands with soap and water not less than 20 seconds and staying home as much as possible were the first basic recommendations in order to slow disease spread [2]. Incubation period of Covid-19 changes between 5 to 15 days [3]. Novel data about Covid-19 are 1934125 cases, 12437 death and 456599 recovered people at 14th April of 2020 according to the global media. 61049 cases, 1296 death and 3957 recovered people were seen in Turkey with 410556 total test number at the same day.

There were 17 million new cases of cancer worldwide in 2018. Four most common cancer occurring worldwide are lung, breast, bowel and prostate cancer. There will be 27 million new cases of cancer each year by 2040. There were 9.6 million death from cancer worldwide in 2018. Lung, liver, stomach and bowel are the most common causes of cancer death. Radiotherapy is one of the irreplaceable and corner stone treatment modalities for the cancer treatment. Problematic issue with Covid-19 pandemia was how to maintain the radiotherapy department activity with protecting firstly cancer patients, families and healthcare providers including radiation oncologists, physicists, radiotherapy technicians, nurses and other healthcare givers with whole department workers.

\section{Problems and Recommendations}

There are 7 problems needed to be given high importance for the cancer patients and the radiotherapy staff associated with radiation treatment.

1. Do not panic but protect yourself and your staff with proper equipment. Read the updated guidelines and recommendations. Share your experience with other healthcare givers. 
2. First of all, radiotherapy should be managed if it is indicated in this pandemic period [4].

3. Safety of health professionals, patients and care givers must be ensured. Triage point at the entrance of hospital should be activated to follow the possible Covid-19 positive population including patients and caregivers [5]. Hand disinfection solutions should be provided in entrance, treatment facilities and clinics. Masks should be weared by patients, families and all health care providers.

4. Third problem is how to act with the symptomatic, suspector Covid-19 infected patients and healthcare professionals. The patients with cough, dyspnea or subfebrile fever associated with the ongoing cancer morbidity must wear a mask and maintain their radiotherapy courses. The patient group including symptomatic Covid-19 test positive, asymptomatic but incidental PCR test positive, symptomatic, PCR negative but thorax CT is compatible with Covid-19 should not be treated with radiotherapy and also stopped if RT initiated before by the time of end of infection treatment and getting negative PCR tests.

5. Organizing professionals in radio therapy facility is a must for the prevention and maintaining the cancer treatment. Mask should be weared by personnel and disinfectant solutions should be used before and after treatments [6]. The treatment rooms should be disinfected after every treatment of patient quickly. The staff should not be in close contact less than 1-meter. Shift system might be organized by administration of department.

6. Limiting the cancer patients for the access of radiotherapy departments should be managed for optimal care and protection of Covid-19 infection. Hypofractionation must be encouraged if possible. Delay follow-up visits after talking to the patients. Benign and functional disease treatment with radiotherapy should be postponed. Radical radiotherapy of low-intermediate prostate cancer or adjuvant radiotherapy of low-risk breast cancer with DCIS (ductal carcinoma in situ) or etc. might be delayed.

7. Stay positive and keep your energy and your team to get rid of this pandemia closely soon using all the guidelines, experiences among Wuhan and all over the World.

\section{Conclusion}

Too bey all the rules and recommendations will keep the cancer patients and health care givers to get infected with novel coronavirus. Do not forget the cancer patients are possibly immune supressed and have a tendency to all infectious diseases.

\section{References}

1. (2020) World Health Organization. Director-General's remarks at the media briefing on 2019-nCoV.

2. (2020) World Health Organization. Director-General's opening remarks at the media briefing on COVID-19.

3. Rothe C, Schunk M, Sothmann P (2020) Transmission of 2019-nCov infection from an asymptomatic contact in Germany. New England Journal of Medicine 382(10): 970-971.

4. (2019) The Royal College of Radiologists: Timely delivery of radical radiotherapy: Guidelines for the management of unscheduled treatment interruptions, $\left(4^{\text {th }}\right.$ edn), Royal College of Radiologists, Holborn, London WC2A 3JW, UK.

5. Filippi AR, Russi E, Magrini SM, Corvo R (2020) Letter from Italy: First practical indications for radiation therapy departments during COVID-19 outbreak. International Journal of Radiation Oncology Biology and Physics 107(3): 597-599.

6. (2020) World Health Organization. Advice on the use of masks in the community, during home care and in the healthcare settings in the context of the novel coronavirus (2019-nCov) outbreak. 